\title{
Silicic acid mediated formation of tannic acid nanocoatings
}

\author{
Florian Weber $^{\dagger}$, Alejandro Barrantes ${ }^{\dagger}$, Hanna Tiainen ${ }^{\dagger *}$ \\ ${ }^{\dagger}$ Department of Biomaterials, Institute of Clinical Dentistry, University of Oslo, P.O. Box 1109 Blindern, o317 Oslo, \\ Norway
}

\begin{abstract}
Tannic acid (TA) adheres to a broad variety of different materials and forms versatile surface coatings for technical and biological applications. In mild alkaline conditions, auto-oxidation processes occur and a firm monolayer is formed. Up to now, thicker coatings are only obtained in cross-linked multilayer fashion. This study presents an alternative method to form continuous TA coatings using ortho-silicic acid ( $\left.\mathrm{Si}_{\mathrm{aq}}\right)$. Adsorption kinetics and physical properties of TA coatings in the presence of $\mathrm{Si}_{\mathrm{aq}}$ were determined using a quartz crystal microbalance (QCM-D) and nanoplasmonic spectroscopy (NPS). An in situ TA layer thickness of $200 \mathrm{~nm}$ was obtained after $24 \mathrm{~h}$ in solutions supplemented with $80 \mu \mathrm{M}$ $\mathrm{Si}_{\mathrm{aq}}$. Dry state measurements indicated a highly hydrated layer in situ. Furthermore, chemical analysis by FTIR spectroscopy revealed possible complexation of TA by $\mathrm{Si}_{\mathrm{aq}}$, whereas UV-vis spectroscopy did not indicate an interaction of $\mathrm{Si}_{\mathrm{aq}}$ in the auto-oxidation process of TA. Investigation of additional metalloid ions showed that germanic acid was also able to initiate a continuous coating formation of TA, whereas boric acid prevented the polymerization process. In comparison to TA, the coating formation of pyrogallol (PG) and gallic acid (GA) was not affected by $\mathrm{Si}_{\text {aq }}$. PG formed continuous coatings also without $\mathrm{Si}_{\mathrm{aq}}$, while GA only formed a monolayer in presence of $\mathrm{Si}_{\mathrm{aq}}$. However, $\mathrm{Si}_{\mathrm{aq}}$ induced a continuous layer formation of ellagic acid (EA). These results indicate the specific importance of ortho-silicic acid in the coating formation of polyphenolic molecules with multiple ortho-dihydroxy groups and open new possibilities to deposit TA on interfaces.
\end{abstract}

\section{INTRODUCTION}

Surface modification using polyphenolic molecules have gained increasing interest during the last decade..$^{1-4}$ After a thorough screening of different polyphenolic molecules by Sileika et al. and Barret et al., which identified several polyphenols capable of forming coatings, ${ }^{5-6}$ polyphenolic coatings have been studied to create antifouling surfaces, ${ }^{7-10}$ antibacterial surfaces,, , 11 and for subsequent immobilization of functional molecules.3, 12-13

The interaction of polyphenolic molecules with various surfaces has been extensively studied for catechols, such as polydopamine. ${ }^{14-16}$ These studies have shown that polyphenolic groups are able to interact via several mechanisms. Amongst the proposed pathways are hydrogen bonding, cation- $\pi$-interactions, coordination chemistry, and covalent bonding. ${ }^{17}$ However, the coating formation beyond the nature of a monolayer does not always correlate with the initial mode of interaction. Commonly, the subsequent layer is formed via crosslinking mechanisms, which are based on the capacity of the vicinal diol groups to complex metal ions. ${ }^{18}$ These so-called metal phenolic networks (MPN) are usually prepared using transition metal ions, such as $\mathrm{Fe}^{3+}, \mathrm{Al}^{3+}, \mathrm{Cu}^{2+}$, and $\mathrm{Mn}^{2+}$ cations. ${ }^{19-22}$

In addition, the intrinsic auto-oxidation in aqueous solution can initiate the polymerization of polyphenolic molecules that enables the coating formation. ${ }^{23-24}$ The oxidation of phenolic hydroxyl groups by dissolved oxygen forms quinones and semi-quinones, ${ }^{25}$ which couple via secondary interactions, such as hydrogen bonding, ${ }^{26}$ interaction of electron donor-acceptor systems ( $\pi$-stacking), ${ }^{27}$ or proceed to form primary bonds. ${ }^{28}$ In the latter case, new inter- and intramolecular $\mathrm{C}-\mathrm{C}$ and $\mathrm{C}-\mathrm{O}$ bonds are formed via a cascade of radical reactions. ${ }^{29-30}$

The first kinetic study of TA deposition using quartzcrystal microbalance with dissipation monitoring (QCMD) revealed a monolayer formation of tannic acid on gold and silica sensors. ${ }^{3}$ These results have later been contrasted in a study by Geißler et al., who reported coating thicknesses of tannic acid up to $60 \mathrm{~nm} .^{32}$ Their report further included XPS data, which indicated silicon in their coatings. While the coating formation was shown to be dependent on $\mathrm{pH}$ and ionic strength, the authors did not address the role of silicon. It has however been reported that silicic acid is able to catalyze catechol degradation and to complex ortho-diphenolic compounds. $33-36$

In the present study, we investigate this controversial finding by means of QCM-D and NPS and elucidate the significant importance of ortho-silicic acid on the formation of tannic acid nanocoatings. Additionally, we support our results by studying the influence of germanic acid and boric acid on the deposition process of TA and further compare the coating formation of TA to the 
polyphenolic molecules gallic acid, pyrogallol, and ellagic acid.

\section{EXPERIMENTAL SECTION}

Materials. Tannic acid (ACS grade, Sigma Aldrich, MW $=1701.2, \quad$ LOT\#MKBN9606V), gallic acid (97.5-102.5\%, Sigma Aldrich, $\quad M W=170.1$, LOT\#SLBSoo 48V), and pyrogallol (ACS grade, Sigma Aldrich, MW = 126.1, LOT\#MKBS3610V) were dissolved at a concentration of $1 \mathrm{mg} / \mathrm{ml}$ in aqueous buffer. Ellagic acid solutions ( $\geq 95 \%$, Sigma Aldrich; $\mathrm{MW}=302.2$, LOT\#BCBX0568) were prepared by stirring $0.5 \mathrm{mg} / \mathrm{ml}$ in buffer overnight and filtering off undissolved residue using a $0.22 \mu \mathrm{m}$ nitrocellulose membrane. Unless stated, other chemicals were purchased from Sigma Aldrich or VWR in ACS grade.

Buffer solutions consisted of $100 \mathrm{mM}$ bicine supplemented with $600 \mathrm{mM} \mathrm{NaCl}$ and were adjusted with 1o $\mathrm{M} \mathrm{NaOH}$ to $\mathrm{pH} 7.8$. All solutions were stored in plastic bottles to avoid dissolution of silica ions from glassware. Ortho-silicic acid (sodium metasilicate pentahydrate, $\geq 95 \%$, Sigma Aldrich), boric acid ( $\geq 99.5 \%$, Sigma Aldrich), and germanic acid (germanium (IV) oxide, $\geq 99.99 \%$, Sigma Aldrich) stock solutions were prepared in milliQ water.

OCM-D. To monitor the kinetics of the in situ coating formation, a quartz crystal microbalance with dissipation monitoring (QSense E4, BiolinScientific) was used. Unless stated, measurements were performed with $\mathrm{Ti}$ coated sensors (QSX 310, BiolinScientific). Prior to use, the sensors were sonicated for $15 \mathrm{~min}$ in $2 \%$ sodium dodecyl sulfonate (SDS), rinsed with water and ethanol, and treated for $15 \mathrm{~min}$ in a UV-ozone cleaner (Novascan PSD-UV4). After equilibration of the sensor in buffer and recording a baseline at $21^{\circ} \mathrm{C}$, polyphenolic solutions were flown through the cells at a rate of $100 \mu \mathrm{l} / \mathrm{min}$. During the measurement, the solutions were stirred at $100 \mathrm{rpm}$ to supply a sufficient amount of oxygen for the reaction. After the measurement, the cells and sensors were cleaned with $0.1 \mathrm{M} \mathrm{HCl}$ for 5 min followed by intensive flushing with $2 \%$ SDS and milliQ water.

NPS. The dry mass of adsorbed polyphenolic molecules was determined using nanoplasmonic spectroscopy (Acoulyte, Insplorion $\mathrm{AB}$ ). The instrument uses the QCM-D setup with modified QSense sensors and an addon for window module QCM-D chambers. Sensors supplied by Insplorion feature gold nanodiscs that create surface plasmons upon irradiation by a white light source. To correlate the change in refractive index to other QCM-D measurements, sensors with a $\mathrm{TiO}_{2}$ top layer were used. Prior to experiments, sensors were immersed in $2 \%$ SDS solution for 15 min, rinsed with water and ethanol, and UV-ozone treated for $15 \mathrm{~min}$ to remove contaminations. The sensors were then equilibrated in buffer until a stable baseline was obtained. Subsequently, the adsorption of polyphenolic molecules was monitored under the same conditions as in the QCM-D setup described above $\left(21^{\circ} \mathrm{C}, 100 \mu \mathrm{l} / \mathrm{min}\right.$, 100 rpm).

Ellipsometry. Commercial silicon wafers (Sigma Aldrich, (100), n-type) were cut to a format of $1 \mathrm{~cm} \times 1 \mathrm{~cm}$ and used as optically flat substrates. Prior to the coating process, the substrates were UV-ozone treated for $15 \mathrm{~min}$ and boiled in a $5 / 1 / 1$ solution of water, ammonia $(25 \%)$, and $\mathrm{H}_{2} \mathrm{O}_{2}(30 \%)$ for $10 \mathrm{~min}$ to remove any organic contaminants. Subsequently, the wafers were treated with $10 \%$ hydrofluoric acid for $10 \mathrm{~min}$ to yield hydrophobic surfaces. The substrates were vertically positioned in a custom-made holder and immersed in $200 \mathrm{ml}$ tannic acid solution. During the coating deposition, the solution was stirred with a magnetic stirrer at $100 \mathrm{rpm}$.

The film thickness of TA was determined three times across the area of three individual substrates with a Rudolf Auto EL III (Rudolf Research) null ellipsometer. The calculation model assumed a single layer with the same refractive index of the polyphenolic film as $\mathrm{SiO}_{2}$ $\left(n_{R}=1.46\right)$. The native oxide layer of silicon was initially determined and subtracted from all results.

AFM. Dry state layer thickness and topographical analysis was evaluated with an atomic force microscope (MFP 3D, Asylum Research). Using the cantilever (ACS240TS) an area of $10 \mu \mathrm{m} \times 10 \mu \mathrm{m}$ was scratched and subsequently scanned in contact mode. The height differences were obtained from the line profiles across the scratched edge for three randomly distributed spots across the substrate surface.

FTIR. Tannic acid precipitates were collected by filtration of the reaction solution through a $0.22 \mu \mathrm{m}$ nitrocellulose membrane. The filtrate was washed with milliQ water to remove excess buffer salts, dried, and scanned using a universal ATR sampler (Spectrum 400, Perkin Elmer). Spectra were recorded at a resolution of $1 \mathrm{~cm}^{-1}$ and averaged over 16 measurements to improve the signal to noise ratio. The data was processed by correction for ATR features and baseline subtraction.

UV-Vis. The degree of oxidation of dissolved polyphenolic molecules was assessed using UV-vis spectroscopy (Lambda 25, PerkinElmer). Spectra from $250-800 \mathrm{~nm}$ were recorded with a resolution of $1 \mathrm{~nm}$. Solutions were filtered through a $0.2 \mu \mathrm{m}$ polyether sulfone syringe filter prior to measurements to remove any particles. Due to strong absorbance in the UV range, the polyphenolic solutions were diluted at a ratio of 1:100 for measurements between $250-400 \mathrm{~nm}$.

EDS. The atomic composition of filtered and dried phenolic precipitate was analyzed by energy dispersive $\mathrm{x}$ ray spectroscopy (EDS). Measurements were performed on an analytical benchtop SEM (TM3030, Hitachi HighTechnologies Corporation) coupled with an EDS system (Quantax 7o, Bruker). EDS spectra were obtained in EDS (high current, $15 \mathrm{kV}$ ) and charge reduction mode.

\section{RESULTS AND DISCUSSION}


Tannic acid solutions were prepared in bicine buffer at $\mathrm{pH} 7.8$ and deposited onto QCM-D sensors under constant flow to comply with previously reported conditions by Geißler et al. ${ }^{22}$ We observed that adsorption of TA onto titanium surfaces from buffer without silicic acid formed a stable layer after 5 min (Figure $1 \mathrm{~A}$ ). A decrease of $\sim 19 \mathrm{~Hz}$ in the oscillation frequency corresponds to a Sauerbrey mass of $377 \pm 21 \mathrm{ng} / \mathrm{cm}^{2}$. This is equivalent to a thickness of $1.8 \pm 0.1 \mathrm{~nm}$ assuming a density of a firm initial layer of $2120 \mathrm{~kg} / \mathrm{m}^{3}$. Although the theoretical dimension of TA is $28 \AA$, the naturally derived product might consist of less than ten gallic acid groups. Further, taking into consideration the uncertainties in the surface coverage and the sensitivity of the Sauerbrey equation, a monolayer of TA adsorbed in an orthogonal position on the surface can be assumed. Similar monolayer formation has previously been reported by Ball et al. However, their experiments were conducted in non-oxidizing conditions at $\mathrm{pH}$ 5.o. ${ }^{31}$ Hence, our result complements their findings in oxidizing conditions. After $2 \mathrm{~h}$, the auto-oxidation process led to polymerization of TA and an exponential decrease in the frequency was observed. Simultaneously the dissipation increased, indicating that oscillation energy is lost. This effect is caused by particles formed by the oxidation mediated polymerization of TA. ${ }^{29}$ These particles sediment onto the sensor surface and once they loosely attach, they slip and dissipate energy. ${ }^{37}$ Since the shear wave penetration depth is inversely proportional to the oscillation frequency, higher overtones have higher sensitivity close to the surface. Thus, the observed split of the overtones in the frequency signal also indicates the inhomogeneous layer structure.

This result was contrary to the TA deposition reported by Geißler et al. and their coating formation might originate from their determined $\mathrm{Si}$ contamination. ${ }^{32}$ Therefore, the effect of ortho-silicic acid $\left(\mathrm{Si}_{\mathrm{aq}}\right)$ on the layer formation was explored by screening through a deliberately added concentration between $1 \mu \mathrm{M}$ and $1000 \mu \mathrm{M}$ (Figure $\mathrm{S} 1$ ). A minimum amount of $10 \mu \mathrm{M} \mathrm{Si} \mathrm{i}_{\mathrm{aq}}$ $\left(\mathrm{n}_{\mathrm{TA}} / \mathrm{n}_{\mathrm{Si}}=58.8\right)$ was found necessary to initiate TA layer formation. Concentrations above $90 \mu \mathrm{M} \mathrm{Si} \mathrm{iq}_{\mathrm{aq}}$ led to increased turbidity of the solution (Figure S2) and the precipitation reduces the concentration of surfacereactive TA. We chose a concentration of $80 \mu M\left(n_{T A} / n_{\mathrm{Si}}\right.$ $=7 \cdot 3$ ) as reference for subsequent experiments to best mimic the deposition kinetics previously reported by Geißler et al.32 Additionally, we observed that both $\mathrm{Si}_{\mathrm{aq}}$ and $\mathrm{NaCl}$ have a synergistic effect under oxidizing conditions. Supplementing only one of both molecules did not lead to the deposition of TA films. (Figure $\mathrm{S}_{3}$ ). Possible reasons for the need of $\mathrm{NaCl}$ might be a charge screening effect ${ }^{38}$ or radical anion stabilization, ${ }^{39}$ which enables the interaction with silicic acid.

The layer formation of TA in bicine buffer with $80 \mu \mathrm{M}$ $\mathrm{Si}_{\mathrm{aq}}$ showed that after the initial adsorption, the frequency continued to decrease during the first $8 \mathrm{~h}$ until it leveled out at approximately $-1180 \mathrm{~Hz}$ (Figure $1 \mathrm{~B}$ ). The dissipation increased from $\sim 0.4 \times 10^{-6}$ after $15 \mathrm{~min}$ to $\sim 25 \times 10^{-6}$ after $2 \mathrm{~h}$. At this point, the overtones started to split due to particle formation in the solution. After $8 \mathrm{~h}$, the adsorbed layer did not gain mass, but became more dissipative. This may be an effect of the layer of sedimented particles on the surface of the sensor, which became thicker with time and limited additional reactions at the surface. ${ }^{32}$ This is an inherent problem of the used QCM-D system that can be prevented by an upside-down setup as shown in Figure $\mathrm{S}_{4}$. Preventing sedimentation on the sensor, led to a stable dissipation below $\sim 30 \times 10^{-6}$ after $8 \mathrm{~h}$. In this setup, the negative shift in frequency was significantly higher $\sim 1600 \mathrm{~Hz}$, however still leveled off after $8 \mathrm{~h}$, suggesting that most of the molecules have reacted.

The obtained TA coatings were also tested towards their stability in different environments. While both strong acidic and strong alkaline conditions disintegrated the coatings, we observed good stability in water containing $600 \mathrm{mM} \mathrm{NaCl}$ (Figure $\mathrm{S}_{3}$ ). 
Surface dependent adsorption of TA. The conformation TA adopts on the surface might influence the subsequent interaction with other molecules. To exclude that the continuous layer formation is determined by the initial mode of interaction of TA, different types of sensors were tested $\left(\mathrm{SiO}_{2}, \mathrm{Au}\right.$, hydroxyapatite (HA), and $\left.\mathrm{Ti}\right)$. On inorganic surfaces, the main interactions of polyphenolic molecules are based on hydrogen bonding and coordination chemistry. ${ }^{17}$ On titanium surfaces, the vicinal hydroxyl groups of polyphenolic molecules have been reported to form coordination complexes with $\mathrm{Ti}^{4{ }^{-}-}$ ${ }^{41}$ As shown in Figure $\mathrm{S}_{5}$, slight variations in the initial adsorption processes on different surfaces were observed. Especially silica surfaces exhibited significantly lower adsorption of TA from buffer without $\mathrm{Si}_{\mathrm{aq}}$. Only half the frequency and dissipation shift was obtained compared to Ti sensors. This might be due to the higher negative surface charge of silica and its highly hydrophilic character compared to $\mathrm{TiO}_{2} \cdot{ }^{42}$ After $24 \mathrm{~h}$, the deposited layers in the presence of $\mathrm{Si}_{\mathrm{aq}}$ resulted in frequency shifts of approximately $-970 \mathrm{~Hz}$ on $\mathrm{Au},-1150 \mathrm{~Hz}$ on $\mathrm{SiO}_{2}$, and $1490 \mathrm{~Hz}$ on HA surfaces. This concludes that TA might interact differently upon contact with the studied

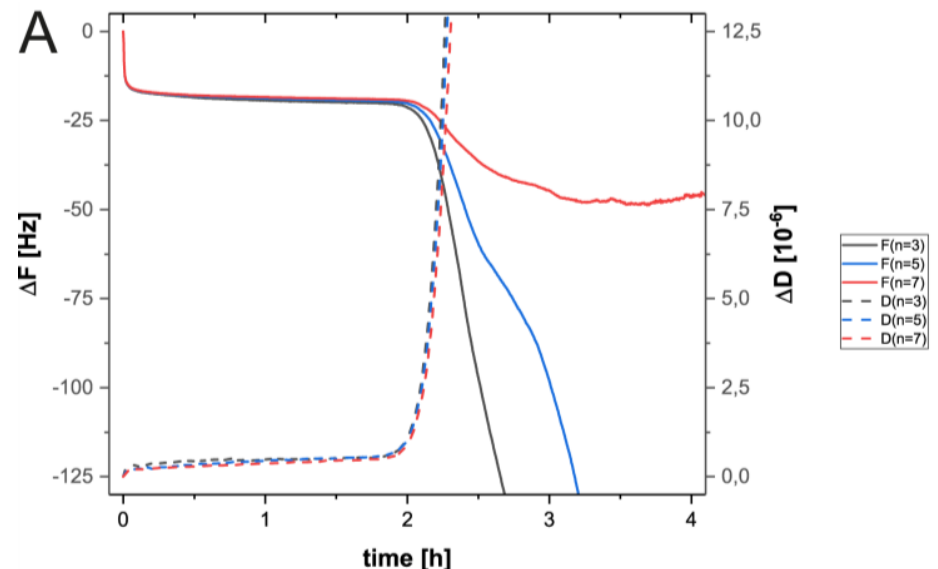

surfaces. The differing initial adsorption however did not affect the subsequent TA deposition. In general, TA only formed a continuous coating if the buffer was supplemented with $\mathrm{Si}_{\mathrm{aq}}$. Furthermore, no effect was observed by pre-absorption of $\mathrm{Si}_{\mathrm{aq}}$ onto the surface (data not shown) that would indicate a silicic acid mediated change in TA conformation.

QCM-D verification and TA layer characterization. To get further insight on the physical properties of the coating, we complemented the QCM-D data with nanoplasmonic spectroscopy. Since NPS senses changes in the refractive index close to the surface, it was used to verify that the initial change in frequency in the QCM-D experiments originates from adsorption of a monolayer and is not caused by a change of physical properties of the solution, such as viscosity and density. In Figure 2, the relative change of the plasmon peak upon adsorption of TA is plotted against time, which shows that the NPS signal for the adsorption from buffer without $\mathrm{Si}_{\mathrm{aq}}$ was similar to the QCM-D signal. After an initial increase, the signal leveled out giving a plasmon peak shift of $\sim 6.2 \mathrm{~nm}$. This confirmed the adsorption of

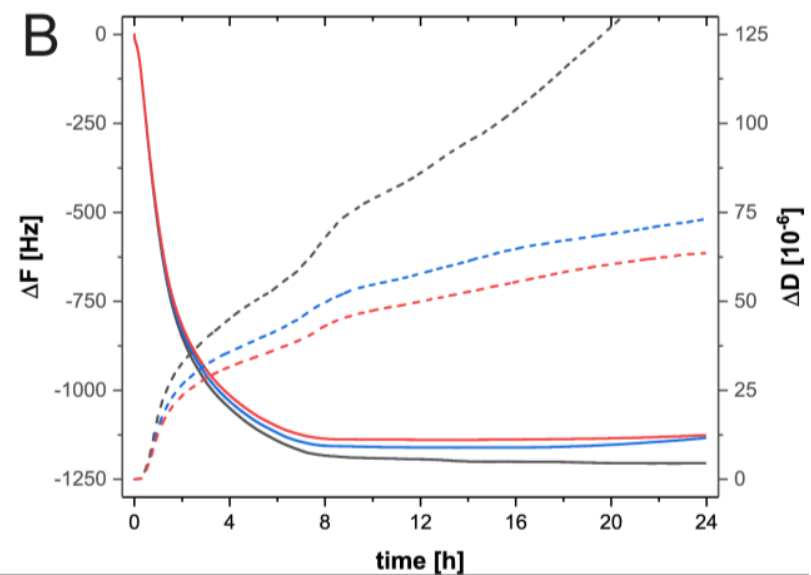

Figure 1: Averaged $(\mathrm{n}=3)$ and normalized frequency and dissipation shifts for the $3^{\text {rd }}, 5^{\text {th }}$, and $7^{\text {th }}$ overtone as a function of time during deposition of tannic acid onto titanium surfaces followed by QCM-D: Adsorption from bicine buffer at $\mathrm{pH} 7.8$ (A) and adsorption from bicine buffer supplemented with $80 \mu \mathrm{M} \mathrm{Si}_{\mathrm{aq}}$ (B).

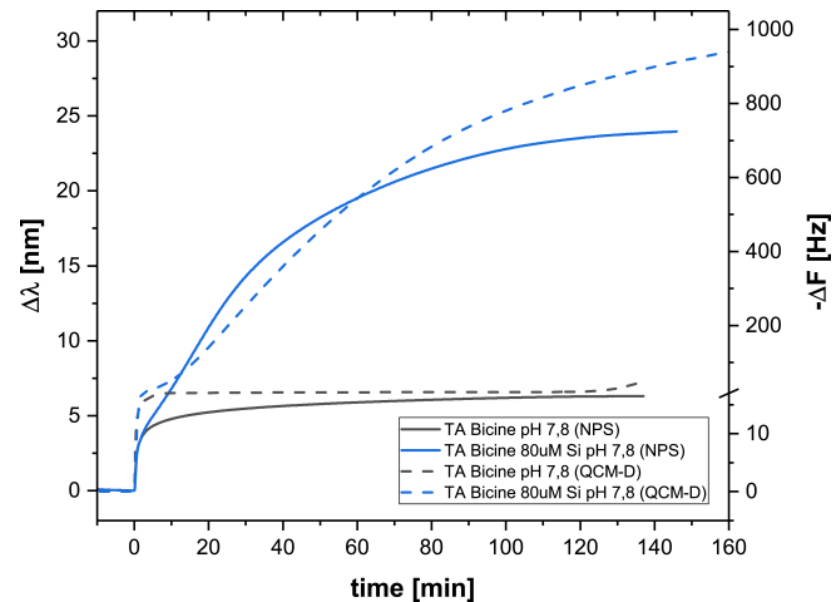

Figure 2: Averaged $(n=2)$ shift of the plasmon peak and normalized frequency of the $3^{\text {rd }}$ overtone as a function of time during deposition of TA onto $\mathrm{TiO}_{2}$ surfaces: TA adsorption supplemented with and without $80 \mu \mathrm{M} \mathrm{Si}_{\mathrm{aq}}$ followed by NPS (solid lines) and QCM-D (dashed lines).

TA monolayer. Adding $80 \mu \mathrm{M} \mathrm{Si}_{\mathrm{aq}}$ to the solution caused a continuous rise during the first $0.5 \mathrm{~h}$. Subsequently, $\Delta \lambda$ leveled out once a peak shift of $\sim 23.9 \mathrm{~nm}$ was reached after $2.5 \mathrm{~h}$. At this point, the frequency signal in the QCM-D was still decreasing. Surface plasmons have a penetration depth of $100 \mathrm{~nm}$, but since they decay exponentially, the effective penetration depth is $30 \mathrm{~nm} .{ }^{43}$ The NPS probing depth is thus three times lower than the penetration depth of the acoustic shear wave of the $7^{\text {th }}$ overtone for QCM-D in liquid environment. ${ }^{44}$ Hence, the difference in both signals indicates that the layer thickness reached the penetration depth of NPS. It is worth mentioning that after $2 \mathrm{~h}$, the presence of particles 
in suspension influenced the intensity of the plasmon signal, even though the signal was still detectable.

Once the limit of the penetration depth was reached, the TA layer density was estimated with Equation $\mathrm{S}_{5}$ to be $1046 \pm 80 \mathrm{~kg} / \mathrm{m}_{3}$. This layer density is very close to the density of the surrounding liquid, which might be caused by a change of the refractive index upon oxidation of TA. However, it indicates that the density of the film in liquid environment is lower than the literature value of TA of $2120 \mathrm{~kg} / \mathrm{m}^{3}$. A comparison of the differences in adsorbed mass sensed by QCM-D and NPS allowed an estimation of the film hydration (Table 1). For the firm initial monolayer, both techniques gave similar results indicating a low hydration and validity of the used NPS parameters. The subsequent determination of the mass in the range of the NPS

Table 1: Estimation of adsorbed mass and correlated thickness of TA in QCM-D and NPS setup.

\begin{tabular}{l|c|c|c}
\hline & QCM-D & NPS & Hydration \\
\hline$\Gamma_{\text {monolayer }}\left[\mathrm{ng} / \mathrm{cm}^{2}\right]$ & $420 \pm 36$ & $390 \pm 58$ & \multirow{2}{*}{$7 \pm 5 \%$} \\
\cline { 1 - 3 } $\mathrm{d}_{\text {monolayer }}[\mathrm{nm}]^{\mathrm{a}}$ & $2.0 \pm 0.2$ & $1.8 \pm 3$ & \\
\hline$\Gamma_{\mathrm{t}=0.5 \mathrm{~h}}\left[\mathrm{ng} / \mathrm{cm}^{2}\right]$ & $3020 \pm 260$ & $2029 \pm 63$ & \multirow{2}{*}{$32 \pm 11 \%$} \\
\cline { 1 - 3 } $\mathrm{d}_{\mathrm{t}=0.5 \mathrm{~h}}[\mathrm{~nm}]^{\mathrm{b}}$ & $30.3 \pm 0.3$ & $19.4 \pm 0.6$ & \\
\hline
\end{tabular}

acalculated with a density of $2120 \mathrm{~kg} / \mathrm{m}^{3}$; b calculated with a density of $1046 \mathrm{~kg} / \mathrm{m}^{3}$; Values are given as mean $(\mathrm{n}=2)$ and error of the mean.

penetration depth using Equation S6 pointed out a higher mass in QCM-D. This was attributed to coupled water sensed in QCM-D,45 which corresponds to a hydration of $\sim 32 \%$.

Adsorbed mass and layer thickness in dry state. Although NPS measures the influence from adsorbed molecules, and thus results in a dry-mass, the thickness of the layer must be known by other means. For QCM-D, the layer density has to be assumed to determine its thickness. To avoid a cross relation between both techniques we additionally measured the TA coating thickness by ellipsometry. The progress of the dry thickness over time is graphed in Figure 3, showing a gradual increase in thickness, which leveled off after $8 \mathrm{~h}$. The logarithmic order reaching a plateau is characteristic of batch reactions in which the concentration of the reactant is decreasing. However, compared to the QCM$\mathrm{D}$ data, a slight increase in the thickness was still noticeable after $8 \mathrm{~h}$. This may be an effect of the different experimental setup during coating of the Si substrates and its reduced limitation in mass transport. In the presence of $80 \mu \mathrm{M} \mathrm{Si} i_{a q}$, TA was deposited up to a thickness of $160 \pm 4 \mathrm{~nm}$ after $24 \mathrm{~h}$. Without adding $\mathrm{Si}_{\mathrm{aq}}$, a TA monolayer thickness of $1.9 \pm 0.1 \mathrm{~nm}$ was confirmed. Due to the assumed refractive index $n_{R}=1.46$ in the calculation model, the ellipsometric values are only valid for comparison within the dataset and the absolute value is not accurate. Therefore, we refined the ellipsometric measurements by AFM to obtain an estimation about the deviation of the modeled thickness from the actual thickness. On average, the thickness obtained by AFM was $\sim 25 \%$ lower than the values obtained with the ellipsometer, which suggests that ellisometrically measured $160 \mathrm{~nm}$ would correspond to a coating thickness of $120 \mathrm{~nm}$. The coating had a clear visual effect that could be used to estimate the coating thickness. The $\mathrm{Si}$ wafer changed color from golden in the range of $30-70 \mathrm{~nm}$, to dark blue $(70-90 \mathrm{~nm})$, and became light blue from $90-120 \mathrm{~nm}$ due to light interference similar to $\mathrm{SiO}_{2}$ layers. ${ }^{46}$ As mentioned in the QCM-D measurements, the coating kinetic depended on the concentration of silicic acid. Under low concentration of $10 \mu \mathrm{M} \mathrm{Si} \mathrm{aq}_{\text {aq }}$ a constant, but slow buildup process reached $25 \mathrm{~nm}$ (AFM) after $24 \mathrm{~h}$ (Figure S6). In case the concentration of $\mathrm{Si}_{\mathrm{aq}}$ was increased to $1000 \mu \mathrm{M}$, TA initially built up faster. Compared to $100 \mu \mathrm{M} \mathrm{Si}$ aq, the process reached its final thickness of $117 \pm 10 \mathrm{~nm}$ (AFM) after $8 \mathrm{~h}$ due to the increased precipitation of TA (Figure S2). The general topography was found to be in line with previous reported AFM images. ${ }^{32}$ A roughness of approximately $27 \mathrm{~nm}$ was found, which was largely governed by small particles adhering to the surface (Figure $\mathrm{S}_{7}$ ).

Comparing the obtained TA coating thicknesses in dry and wet state attested that water was lost upon drying, which caused the phenolic layer to condense. To estimate the density in dry state, we used the QCM-D to obtain the Sauerbrey mass of a dried TA coating and measured the thickness on the same sensor with AFM. After $0.5 \mathrm{~h}$ a layer density of $\sim 2830 \mathrm{~kg} / \mathrm{m}^{3}$ was obtained, which then gradually decreased from $\sim 2550 \mathrm{~kg} / \mathrm{m}^{3}$ after $1 \mathrm{~h}$ to $\sim 2060 \mathrm{~kg} / \mathrm{m}^{3}$ after $2 \mathrm{~h}$. This effect is probably caused by the deposition of larger aggregates, which form with proceeding time, onto the surface. ${ }^{32}$ On average, the density was $2481 \pm 317 \mathrm{~kg} / \mathrm{m}^{3}$, which is close to the literature value of $2120 \mathrm{~kg} / \mathrm{m}^{3}$. The slight increase might be caused by bound ions (Figure S8) and rehydration after drying.

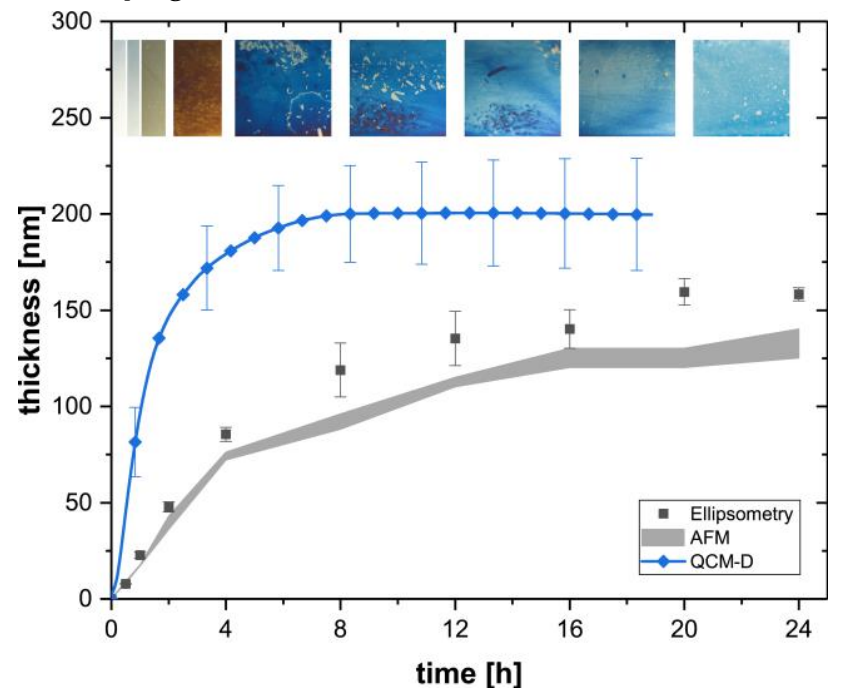

Figure 3: Characterization of layer thickness of tannic acid 
coatings deposited on silicon wafers under supplement of 80 $\mu \mathrm{M} \mathrm{Si}_{\mathrm{aq}}$. Markers show averaged $(\mathrm{n}=9)$ ellipsometric measurements, the gray area represents min./max. AFM values $(n=3)$, and the line represents the average $(n=3)$ of the Voigt modeled QCM-D thickness. Insets depict the silicon wafers changing in color with increasing coating thickness.

It is worth mentioning, that the obtained thickness in dry state is $\sim 60 \%$ below the obtained values in QCM-D. Thus, a difference between the dry thickness and the estimated thickness obtained by NPS remains. We suspect this error is due to our applied average densities, and changes in refractive index upon oxidation.

Analysis of TA oxidation and oxidation products. Since TA was continuously deposited only in the presence of silicic acid, regardless of the substrate, the major interest is the molecular influence of $\mathrm{Si}_{\mathrm{aq}}$ and its mode of interaction. Since TA only formed a monolayer in absence of and $\mathrm{Si}_{\mathrm{aq}}$ pre-adsorption of $\mathrm{Si}_{\mathrm{aq}}$ did not change the coating behavior (data not shown), it can be concluded that $\mathrm{Si}_{\mathrm{aq}}$ is not acting as a bridge between the surface and TA. More likely, $\mathrm{Si}_{\mathrm{aq}}$ interacts with adsorbed TA and dissolved TA in solution. Silicic acid has been shown to act as catalyst in breaking down catechols and promoting the oxidation with dissolved $\mathrm{O}_{2} \cdot 33$ Following the oxidation of TA by UV-vis spectroscopy initially shows two peaks centered at $280 \mathrm{~nm}$ and $320 \mathrm{~nm}$ originating from $\pi-\pi^{*}$ transitions in the conjugated electron system (Figure 4 ). Until $2 \mathrm{~h}$ after the oxidation process started, an increase in intensity was observed followed by a gradual decline. Upon oxidation, the relative height of both $280 \mathrm{~nm}$ and $320 \mathrm{~nm}$ peaks changed and turned opposite. At the same time, TA started to adsorb light in the visible range at $\sim 625 \mathrm{~nm}$. This indicates that the initially delocalized $\pi$-electron system was restructured to form a larger resonance system. However, the general intensity reduction in the UV region might also be caused by a reduced

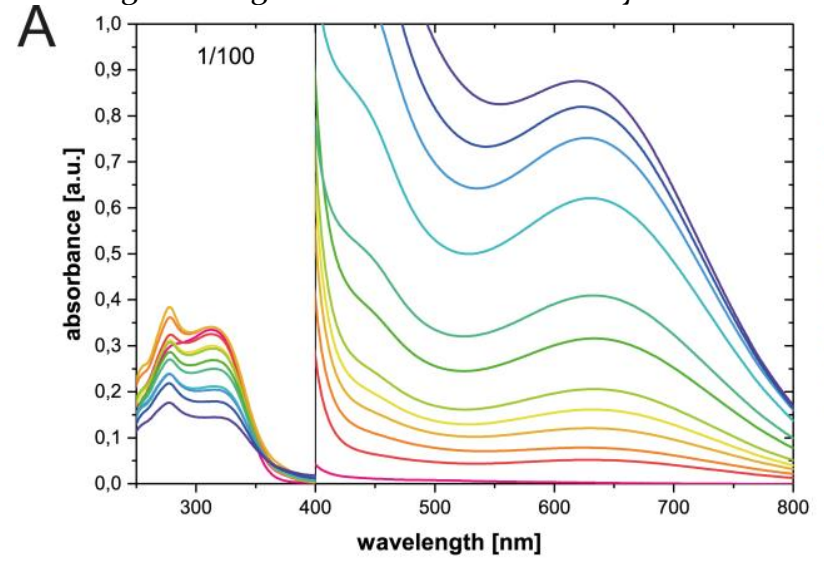

concentration after the formation of larger polymers that were filtered off from the measured samples. The oxidation of TA can thus be followed more precisely based on the peak intensity at $625 \mathrm{~nm}$ that correlates to the darkening of the solution due to oxidation. Comparing the spectra upon addition of $80 \mu \mathrm{M} \mathrm{Si}_{\mathrm{aq}}$ did not show significant differences, which concludes that silicic acid did not

influence the oxidation of TA.

In addition to characterizing the oxidation in solution, we analyzed the TA polymerization product by FTIR spectroscopy (Figure 5). For a detailed description and peak assignment, the reader is referred to Table $S_{1}$ of the supporting information. In general, oxidation of phenolic compounds transforms the phenolic hydroxyl groups into quinones, 47 which induces a change in molecular structure and leads to several differences in the FTIR spectrum of TA polymerization products. The FTIR spectrum of TA precipitates obtained in the presence of $80 \mu \mathrm{M} \mathrm{Si} \mathrm{aq}_{\mathrm{aq}}$ did not show significant differences compared to the bare oxidation product. However, once the $\mathrm{Si}_{\mathrm{aq}}$ concentration was increased to $1000 \mu \mathrm{M}$, solutions became instantly turbid before significant oxidation occurred. The filtered precipitate after $24 \mathrm{~h}$ reaction time showed similarities to in the FTIR spectra unoxidized TA, while subtle differences manifested in the O-H stretching vibration at $3200 \mathrm{~cm}^{-1}$. The reduced intensity and broadened signal might be an indication that the number of $\mathrm{O}-\mathrm{H}$ groups is reduced and more hydrogen bonding occurred..$^{8}$ Further, in the range between $1800 \mathrm{~cm}^{-1}$ to $1400 \mathrm{~cm}^{-1}$ the precipitate is identical to unoxidized TA besides the ring skeletal vibrations at $1504 \mathrm{~cm}^{-1}, 49$ which appeared in the spectrum of oxidized TA. Also the peak shift from $1180 \mathrm{~cm}^{-1}$ to $1190 \mathrm{~cm}^{-1}$ indicated slight oxidation, whereas the following peaks at lower wavenumber are closer resembling unoxidized TA.

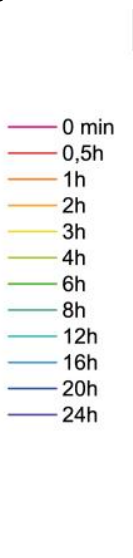

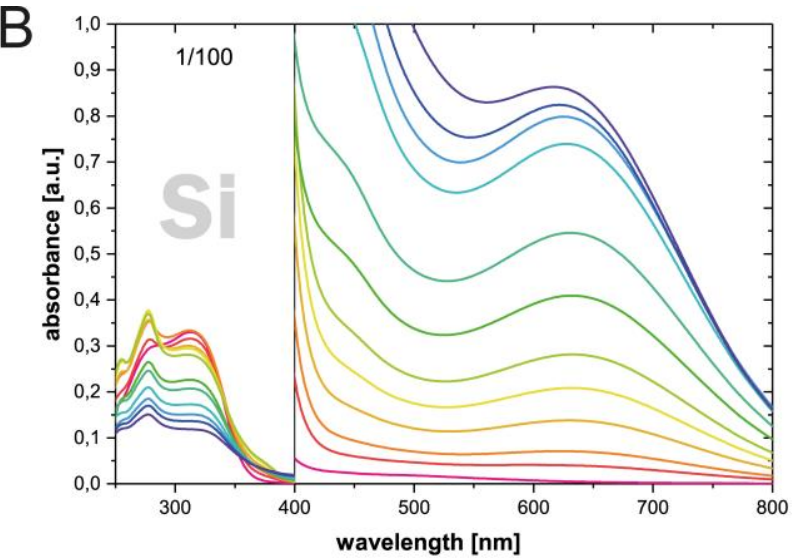

Figure 4: Progress of tannic acid oxidation in bicine buffer at $\mathrm{pH} 7.8$ followed by UV-vis spectroscopy. Oxidation in buffer without $\mathrm{Si}_{\mathrm{aq}}$ (A) compared to oxidation in buffer supplemented with $80 \mu \mathrm{M}$ Siaq (B). The graphs are composed of a 1/10o diluted TA solution in buffer (UV region) and an undiluted TA solution (visible region) merged at $400 \mathrm{~nm}$. 


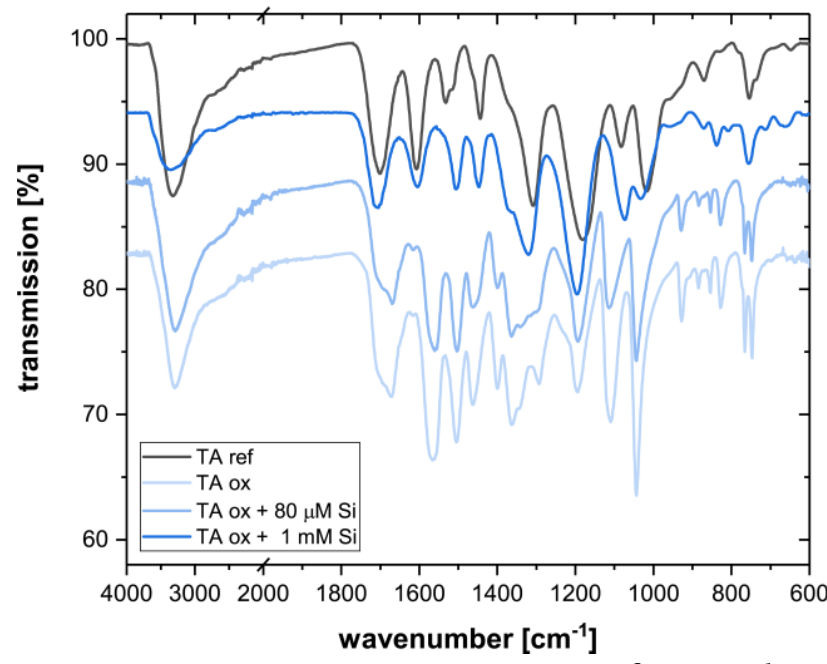

Figure 5: Representative FTIR spectra of TA and its polymerization product obtained after $24 \mathrm{~h}$ under different experimental conditions. Particles formed in $100 \mathrm{mM}$ bicine solution at $\mathrm{pH} 7.8$ with different amount of silicic acid were filtered, dried and analyzed in an ATR setup.

Even though we were able to compare the differences in the organic content of the precipitated particles, silica and organo-silica complexes could not be verified. Corresponding peaks between $1280 \mathrm{~cm}^{-1}$ and $860 \mathrm{~cm}^{-1}$ are close to the existing peaks in either TA or its oxidation product. ${ }^{8}$ However, EDS analysis (Figure S8) validated the presence of $\mathrm{Si}$ in the precipitate. The determined content of $0.4 \% \mathrm{Si}$ in precipitate obtained with a concentration of $80 \mu \mathrm{M} \mathrm{Si} i_{\mathrm{aq}}$ may be too low to detect significant contribution in the FTIR. The fact that high concentration of $\mathrm{Si}_{\mathrm{aq}}$ was observed to result in increased turbidity and precipitation of unoxidized TA, suggests that TA coatings might be formed via complexation by silicic acid. ${ }^{34-35}$ This implies that, unlike for polydopamine, the oxidation mediated polymerization may not be the primary route for the TA coating formation..$^{\circ}$

Influence of other ions in the coating formation of TA. Polyphenolic molecules are known to form coordination complexes with silicic acid. ${ }^{34-36}$ Depending on the coordination state of silicic acid, $\mathrm{Si}(\mathrm{IV})$ and $\mathrm{Si}(\mathrm{V})$ binds two ligands, and $\mathrm{Si}(\mathrm{VI})$ is able to bind three ligands. This property could lead silicic acid to act as a crosslinker for TA molecules and might explain that under nonoxidizing conditions ( $\mathrm{pH}$ 6.8) the solution became turbid without any change in color (Figure S2). It is worth mentioning that without adding $\mathrm{Si}_{\mathrm{aq}}$, TA solutions remained clear and colorless at $\mathrm{pH}$ 6.8.

To investigate the crosslinking hypothesis, we substituted silicic acid with other known complex forming transition metal ions, such as $\mathrm{Al}^{3+}, \mathrm{Fe}^{3+}, \mathrm{Cu}^{2+}$, and $\mathrm{Mn}^{2+} .{ }^{2-22}$ However, both $\mathrm{Al}^{3+}$ and $\mathrm{Fe}^{3+}$ cations interact strongly not only with polyphenols, but also with bicine leading to flocculation. To circumvent the interaction with the buffer, hydrated anions similar to silicic acid may be more suitable. For this purpose, we tested the two elements $\mathrm{B}$ and $\mathrm{Ge}$ that exist in liquid as the acidic solvated structures, boric acid $\left(\mathrm{H}_{3} \mathrm{BO}_{3}\right)$, and germanic acid $\left(\mathrm{H}_{4} \mathrm{GeO}_{4}\right)$.

Boric acid did not induce any coating formation. Even at a concentration of $10 \mathrm{mM}\left(\mathrm{n}_{\mathrm{B}} / \mathrm{n}_{\mathrm{TA}}=17.2\right)$ no continuous coating formation was observed besides the adsorption of a TA monolayer (Figure S9). Boric acid rather prevented any particle formation, even though TA still oxidized. The failure to crosslink TA might originate from the molecular structure of boric acid, which might not be available as tetra coordinated borate anion at $\mathrm{pH} 7.8$. Crosslinking via coordination requires two binding sites. The lack of more than one active coordination site in boric acid may prevent further crosslinking of TA. ${ }^{15}$

Alternatively, dissolved germanic acid has coordination numbers IV and VI. ${ }^{22}$ Thus a substitution of silicic acid with germanic acid as a crosslinker is plausible and complexes of germanium with ortho-diphenols have been previously reported.53 As shown in Figure S1o, germanic acid induced coating build-up only for a short time. According to literature germanic acid is a very strong complex former, ${ }^{54}$ which led to rapid precipitation of TA under our experimental conditions. This depleted reactive molecules from the solution and reduced the amount of molecules available to form a surface coating.

Influence of silicic acid in the coating formation of other polyphenolic molecules. Although our result suggested that Si-TA complexes are formed, no effective crosslinking was observed, as reported for $\mathrm{Fe}^{3+}$ systems, 55 when alternately supplying $\mathrm{Si}_{\mathrm{aq}}$ and $\mathrm{TA}$ in a layer by layer fashion (Figure S11). Thus, it might be possible that catalytic humification of $\mathrm{TA}$ by $\mathrm{Si}_{\mathrm{aq}}$ yields lower molecular weight compounds, which react further in the coating formation. 33 TA is classified as a hydrolysable polyphenolic compound consisting of several gallic acid units esterfied on a glucose unit. Although silicates are rather inefficient catalysts, ${ }^{56-57}$ silicic acid might promote the hydrolysis of the ester bond creating gallic acid fragments.

Therefore, the interaction of silicic acid with gallic acid (GA) and pyrogallol (PG) was studied. GA has previously been found to be unable to form a coating, whereas PG is able to form a coating. ${ }^{6}$ However, impurities of silica in the studies were not addressed and might have influenced the results. Our results confirmed that GA is not able to form a continuous coating at $\mathrm{pH} 7.8$ under various $\mathrm{Si}_{\mathrm{aq}}$ concentrations (Figure $\mathrm{S}_{12}$ ). The analysis with combined NPS and QCM-D showed that the adsorption of GA from a solution supplemented with $80 \mu \mathrm{M} \mathrm{Si}_{\mathrm{aq}}$ led to a frequency shift of approximately $-2.5 \mathrm{~Hz}$ and a plasmon peak shift of $\sim 1.5 \mathrm{~nm}$ (Figure $6 \mathrm{~A}$ ). This correlates to an adsorbed mass density of $59 \pm 1 \mathrm{ng} / \mathrm{cm}^{2}$ in the QCM-D setup and $91 \pm 12 \mathrm{ng} / \mathrm{cm}^{2}$ in NPS. The higher value determined by NPS may be caused by a change of the refractive index upon oxidation, compared to the measured refractive index increment of 0.173 in solution. Assuming a low hydrated layer, the NPS mass 
could be matched to QCM-D by adjusting dn/dc to 0.26 . This value is comparable to reported refractive index increments for condensed polyphenolic molecules..$^{58}$ Using the QCM-D mass and an estimated density of $1.730 \mathrm{~kg} / \mathrm{m}^{3}$, the GA layer thickness resulted in $3.5 \pm 0.8 \AA$. Compared to the distance of $6.8 \AA$ between the phenolic hydroxyl group and the carboxylic hydroxyl group of GA, we suspect that the surface might not be fully covered, or the density is lower due to hydration effects.

This excludes the hypothesis of silicic acid breaking down TA to its main hydrolysis product. However, it supports the assumption of a crosslinking mechanism. Phenolic compounds interact with oxide surfaces by coordination of the phenolic hydroxyl groups, ${ }^{40}$ hence GA exposes only its carboxylic acid group towards the bulk solution. This functional group is not forming coordination complexes with silicic acid. In addition, GA solutions did not become turbid within $24 \mathrm{~h}$ reaction time and no precipitates could be collected. This result is expected to originate from the molecular structure of GA, since there is no second ortho-diphenolic group allowing further crosslinking. Furthermore, influence of $\mathrm{Si}_{\mathrm{aq}}$ on the oxidation of GA was not detected (Figure $\mathrm{S} 13$ ).

PG is a low molecular weight polyphenol closely related to GA. Although its deposition process has been characterized and compared to TA, ${ }^{32}$ mechanistic studies are not available. PG formed a continuous coating under all studied experimental conditions (Figure S12), while no acceleration of the oxidation or interaction in solution by $\mathrm{Si}_{\mathrm{aq}}$ was observed (Figure $\mathrm{S} 13$ ). In the absence of any silicic acid, the NPS displayed a plasmon peak shift of approximately $35 \mathrm{~nm}$ after $14 \mathrm{~h}$, associated with a QCM$\mathrm{D}$ frequency shift of $\sim 15 \mathrm{OHz}$ (Figure $6 \mathrm{~B}$ ). Since the dry thickness of PG coatings is close to the thickness obtained in liquid, Geißler et al. estimated a low hydration of PG films. Therefore, the literature density of PG $\left(1453 \mathrm{~kg} / \mathrm{m}^{3}\right)$ was used to correlate the adsorbed mass to the layer thickness.
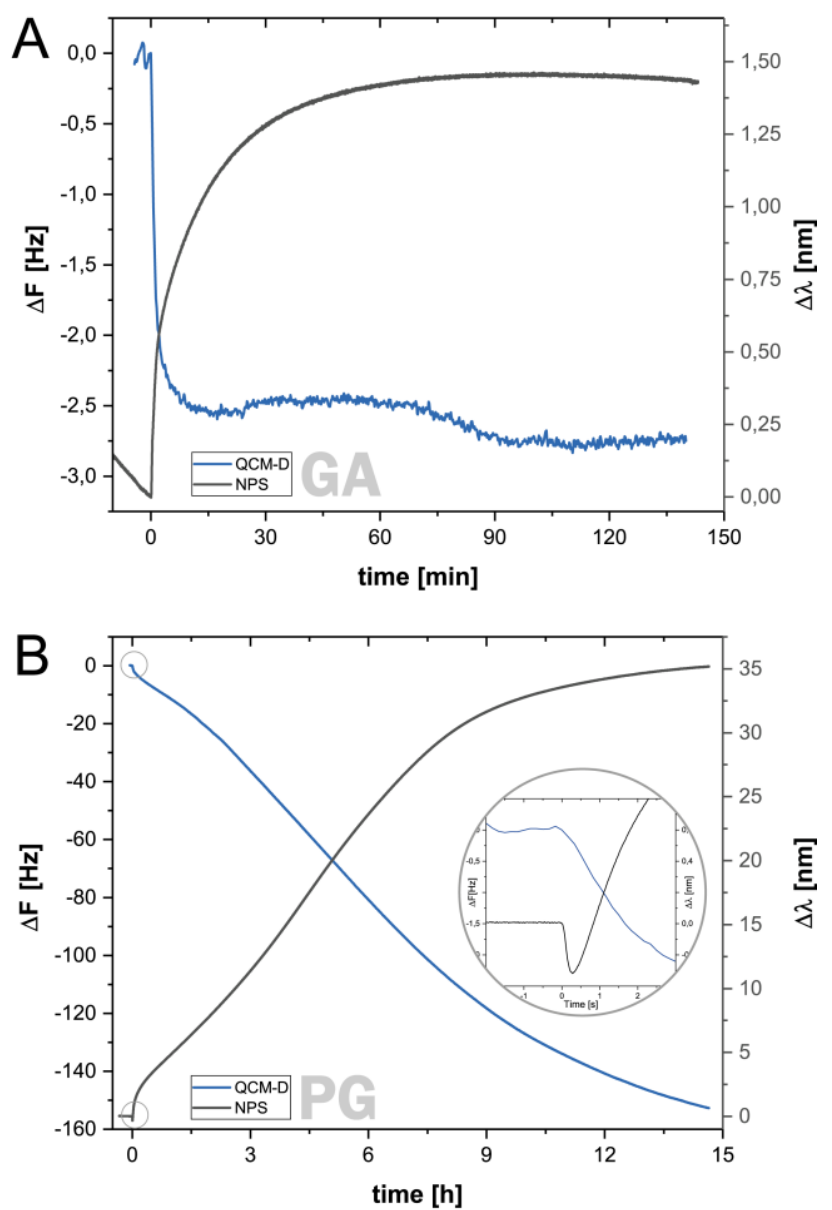

Figure 6: Averaged $(n=2)$ shift of surface plasmon resonance and normalized frequency of the $3^{\text {rd }}$ overtone as a function of time during deposition of gallic acid (A) and pyrogallol (B) onto $\mathrm{TiO}_{2}$ surfaces followed by NPS and QCMD. Addition of $\mathrm{Si}_{\mathrm{aq}}$ did not enable a continuous coating builtup of GA in bicine buffer at $\mathrm{pH} 7.8$, whereas $\mathrm{PG}$ formed a continuous coating even in absence of $\mathrm{Si}_{\mathrm{aq}}$. Inset in panel $\mathrm{B}$ shows a negative peak shift upon PG adsorption.

After $14 \mathrm{~h}$, the QCM-D determined $2885 \pm 344 \mathrm{ng} / \mathrm{cm}^{2}$ adsorbed onto the surface, which corresponds to a thickness of $20 \pm 2 \mathrm{~nm}$. Similarly to GA, we observed increased NPS values of $3902 \pm 10 \mathrm{ng} / \mathrm{cm}^{2}(27 \pm 0.1 \mathrm{~nm})$ for $\mathrm{PG}$ using the determined refractive index increment of o.173. With the assumption of a low hydration, matching NPS and QCM-D values were obtained by adjusting the refractive index increment to $0.24 . .^{8}$

The difference in $\mathrm{dn} / \mathrm{dc}$ may originate from a change in the refractive index upon oxidation and polymerization on the surface. Interestingly, the NPS data showed an unexpected negative peak once PG adsorbs onto the surface (Figure $6 \mathrm{~B}$ ). Since the surface plasmons are very sensitive to the dielectric environment near the sensor surface, 43 this might be an effect of the displacement of ions and water molecules close to the surface. ${ }^{59}$ Further, defects in the $\mathrm{TiO}_{2}$ layer of the sensors may allow direct interaction of PG with the dielectric layer causing this adverse effect. 
These results suggest that the mechanism of the PG coating formation is fundamentally different compared to TA. For small molecular weight polyphenols, intermolecular interactions such as $\pi$-stacking and hydrogen bonding might be possible reaction pathways. ${ }^{18}$ Besides these secondary interactions,

polyphenols polymerize via coupling of quinone intermediates and Michael addition type reactions. ${ }^{1}$ Although the oxidation reaction of PG to purpurogallin has been reported, purpurogallin could not be obtained from carboxylic acid substituted pyrogallols. ${ }^{60}$ Critchlow et al. argued that the carboxyl group reduces the necessary nucleophilic character, which could also explain the difference in the coating formation between PG and GA.

Because the coating characteristics of GA and PG were different, we additionally studied the deposition of ellagic acid (EA). EA overcomes the structural limitations of GA and PG as it features two ortho-diphenolic groups, which might enable crosslinks between the phenolic molecules and $\mathrm{Si}_{\mathrm{aq}}$. Unfortunately, its solubility in bicine buffer at $\mathrm{pH} 7.8$ is limited and even $0.5 \mathrm{mg} / \mathrm{ml}$ EA did not fully dissolve. As a compromise, we used filtered $0.5 \mathrm{mg} / \mathrm{ml}$ EA solutions with unknown concentration, from which EA adsorbed onto titanium surfaces similarly to TA. In buffer without $\mathrm{Si}_{\mathrm{aq}}$, EA led to a decrease of approximately $-8 \mathrm{~Hz}$ after $1 \mathrm{~h}$, which corresponds to an adsorbed mass of $126 \pm 10 \mathrm{ng} / \mathrm{cm}^{2}$. This translates to a layer thickness of $7.5 \pm 0.6 \AA$, assuming a density of $1667 \mathrm{~kg} / \mathrm{m}^{3}$ (Figure 7). The modeled thickness is slightly lower than the theoretical distance of $8.7 \AA$ between the two ortho-dihydroxy groups, and may be caused by disregarded hydration effects.

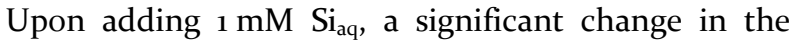
frequency and dissipation was monitored during $8 \mathrm{~h}$ adsorption time. Compared to TA, changes in $\Delta \mathrm{F}$ and $\Delta \mathrm{D}$ of EA exhibit a linear progression (Figure S14). This behavior is typically seen for atom transfer radical polymerizations and indicates a linear chain growth. ${ }^{61}$ After $8 \mathrm{~h}$ the adsorbed mass reached $1180 \pm 70 \mathrm{ng} / \mathrm{cm}^{2}$, which is equivalent to a thickness of $7.0 \pm 0.5 \mathrm{~nm}$. The layer thickness is similar to pyrogallol and thus reasonable for the molecular weight of EA. It is worth mentioning that although $\Delta \mathrm{D} / \Delta \mathrm{F}$ was above $0.02 \times 10^{-6}$, viscoelastic modeling using the Voigt model was not satisfactory and the Sauerbrey model based on the third harmonic was used instead. However, the linearity

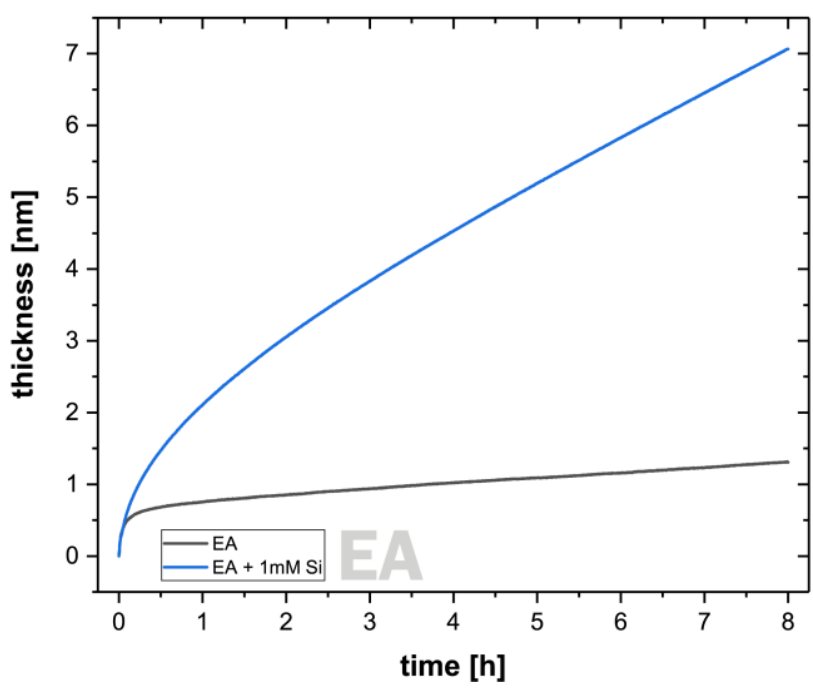

Figure 7: Averaged $(\mathrm{n}=3)$ thickness as a function of time during deposition of ellagic acid onto titanium surfaces. Under addition of $1 \mathrm{mM} \mathrm{Si} \mathrm{aq}_{\mathrm{aq}}$, a progressing layer formation was observed after an initial adsorption of EA from bicine buffer at $\mathrm{pH}$ 7.8. The thickness was obtained using the Sauerbrey model based on the $3^{\text {rd }}$ overtone and a layer density of $1667 \mathrm{~kg} / \mathrm{m}^{3}$.

of the Sauerbrey model is not strictly valid for viscoelastic layers, which are coupled to the crystal oscillation, and might thus constitute to a deviation in the adsorbed mass. ${ }^{62-63}$

In contrast to GA, EA formed a continuous layer in the presence of $\mathrm{Si}_{\mathrm{aq}}$. Although $\mathrm{EA}$ is a relatively stable compound near neutral $\mathrm{pH}$, lactone ring opening might occur in alkaline conditions, ${ }^{64}$ or by alkoxide induced catalysis. ${ }^{65}$ Under the experimental conditions used in this study, ring-opening reactions are unlikely to occur, although side reactions cannot be excluded. Therefore, the continuous deposition of EA may be facilitated by its two coordination sites, further supporting the crosslinking role of silicic acid.

\section{CONCLUSIONS}

In this study, we have shown that tannic acid forms a continuous coating in aqueous buffered systems exclusively in the presence of tetra or higher coordinated metalloid anions. Under our experimental conditions, silicic acid was the most efficient molecule balancing the deposition of TA with its precipitation processes. The overlaying effect of polymerization resulted in a density gradient and an average TA layer hydration of $32 \%$. Our chemical analysis of the TA polymerization products did not conclusively show whether silicic acid acts as a crosslinker or has a catalytic role in the coating process. However, in highly concentrated silicic acid solutions, the turbidity and precipitation of TA in an unoxidized manner, point towards a coordination chemistry between both molecules.

The possibility of a catalytic breakdown of TA into smaller fragments was investigated by studying the 
coating formation of GA and PG. We observed that the primary TA hydrolysis product GA did not form a continuous coating in contrast to PG. GA however features only one ortho-dihydroxy group and would not allow a crosslinking mechanism. EA, which is a bifunctional dimer of GA, was found to form a coating in the presence of silicic acid. Since the kinetics and morphology of TA coatings support the assumption that TA is not degenerated into low molecular weight compounds, we suspect that TA forms coatings via a crosslinking effect of silicic acid. Because the catalytic effect of silicic acid could not be disproven, the exact mechanism of silicic acid in the coating formation of TA requires further physical and chemical analyses of the coating and the oxidation products.

\section{ASSOCIATED CONTENT}

\section{Supporting Information}

The Supporting Information is available free of charge on the ACS Publications website.

Silicic acid concentration series; TA solution turbidity; influence of coating conditions and the stability of TA films; influence of particles in QCMD measurements; substrate dependent TA adsorption; TA dry thickness depending on $\mathrm{Si}_{\mathrm{aq}}$ concentration; EDS and FTIR analysis of TA precipitate; $\mathrm{H}_{3} \mathrm{BO}_{3}$ and $\mathrm{H}_{4} \mathrm{GeO}_{4}$ concentration series; $\quad \mathrm{TA}^{-\mathrm{Si}_{\mathrm{aq}}}$ multilayer system; $\mathrm{Si}_{\mathrm{aq}}$ concentration series for GA and PG deposition; UV-vis analysis of GA and PG; QCM-D raw data for EA deposition. (Word)

\section{AUTHOR INFORMATION}

\section{Corresponding Author}

*E-mail: hanna.tiainen@odont.uio.no

\section{Author Contributions}

The manuscript was written through contributions of all authors. All authors have given approval to the final version of the manuscript.

\section{Notes}

The authors declare no competing financial interest.

\section{ACKNOWLEDGMENT}

This work was funded by the Faculty of Dentistry, University of Oslo. The authors thank Prof. Pentti Tengvall for the support with the ellipsometer measurements and the Scandinavian Society for Biomaterials $(\mathrm{ScSB})$ who funded the research stay of Florian Weber at the University of Gothenburg. Further, we would like to acknowledge Insplorion $\mathrm{AB}$, which provided an Acoulyte demo instrument and assisted with the data analysis. The graphical abstract was illustrated by modifying Servier Medical Art stock graphics.

\section{REFERENCES}

1. Barclay, T. G.; Hegab, H. M.; Clarke, S. R.; GinicMarkovic, M., Versatile Surface Modification Using Polydopamine and Related Polycatecholamines: Chemistry, Structure, and Applications. Adv. Mater. Interfaces 2017, 4 (19), 1601192-n/a.

2. Ejima, H.; Richardson, J. J.; Caruso, F., Metal-Phenolic Networks as a Versatile Platform to Engineer Nanomaterials and Biointerfaces. Nano Today 2017, 12, 136-148.

3. $\quad$ Reitzer, F.; Allais, M.; Ball, V.; Meyer, F., Polyphenols at Interfaces. Adv. Colloid Interfac. 2018, 257, 31-41.

4. Ryu, J. H.; Messersmith, P. B.; Lee, H., Polydopamine Surface Chemistry: A Decade of Discovery. ACS Appl. Mater. Inter. 2018, 10 (9), 7523-7540.

5. $\quad$ Sileika, T. S.; Barrett, D. G.; Zhang, R.; Lau, K. H. A.; Messersmith, P. B., Colorless Multifunctional Coatings Inspired by Polyphenols Found in Tea, Chocolate, and Wine. Angew. Chem. Int. Ed. Engl. 2013, 52 (41), 10766-10770.

6. Barrett, D. G.; Sileika, T. S.; Messersmith, P. B., Molecular Diversity in Phenolic and Polyphenolic Precursors of Tannin-Inspired Nanocoatings. Chem. Commun. 2014, 50 (55), 7265-7268.

7. $\quad$ Kim Hee, J.; Kim, D. G.; Yoon, H.; Choi, Y. S.; Yoon, J.; Lee, J. C., Polyphenol/FeIII Complex Coated Membranes Having Multifunctional Properties Prepared by a One-Step Fast Assembly. Adv. Mater. Interfaces 2015, 2 (14), 1500298.

8. Yang, L.; Han, L.; Liu, Q.; Xu, Y.; Jia, L., Galloyl Groups-Regulated Fibrinogen Conformation: Understanding Antiplatelet Adhesion on Tannic Acid Coating. Acta Biomater. 2017, 64 (Supplement C), 187-199.

9. Zhao, X.; Zhang, R.; Liu, Y.; He, M.; Su, Y.; Gao, C.; Jiang, Z., Antifouling Membrane Surface Construction: Chemistry Plays a Critical Role. J. Membr. Sci. 2o18, 551, 145-171.

10. Zhong, Q.-Z.; Pan, S.; Rahim, M. A.; Yun, G.; Li, J.; Ju, Y.; Lin, Z.; Han, Y.; Ma, Y.; Richardson, J. J.; Caruso, F., Spray Assembly of Metal-Phenolic Networks: Formation, Growth, and Applications. ACS Appl. Mater. Inter. 2018, 10 (39), 33721-33729.

11. Guo, J.; Sun, W.; Kim, J. P.; Lu, X.; Li, Q.; Lin, M.; Mrowczynski, O.; Rizk, E. B.; Cheng, J.; Qian, G.; Yang, J., Development of Tannin-Inspired Antimicrobial Bioadhesives. Acta Biomater. 2018, 72, 35-44.

12. Pranantyo, D.; Xu, L. Q.; Neoh, K.-G.; Kang, E.-T.; Ng, Y. X.; Teo, S. L.-M., Tea Stains-Inspired Initiator Primer for Surface Grafting of Antifouling and Antimicrobial Polymer Brush Coatings. Biomacromolecules 2015, 16 (3), 723-732.

13. Atacan, K.; Özacar, M.; Özacar, M., Investigation of Antibacterial Properties of Novel Papain Immobilized on Tannic Acid Modified Ag/CuFe2O 4 Magnetic Nanoparticles. Int. J. Biol. Macromol. 2018, 109, 720-731.

14. Lee, H.; Scherer, N. F.; Messersmith, P. B., SingleMolecule Mechanics of Mussel Adhesion. Proc. Natl. Acad. Sci. U.S.A. 2006, 103 (35), 12999-13003.

15. Yu, J.; Wei, W.; Menyo, M. S.; Masic, A.; Waite, J. H.; Israelachvili, J. N., Adhesion of Mussel Foot Protein-3 to $\mathrm{TiO}_{2}$ Surfaces: The Effect of $\mathrm{pH}$. Biomacromolecules 2013, 14 (4), 10721077 .

16. Rapp, M. V.; Maier, G. P.; Dobbs, H. A.; Higdon, N. J.; Waite, J. H.; Butler, A.; Israelachvili, J. N., Defining the CatecholCation Synergy for Enhanced Wet Adhesion to Mineral Surfaces. J. Am. Chem. Soc. 2016, 138 (29), 9013-9016.

17. Saiz-Poseu, J.; Mancebo-Aracil, J.; Nador, F.; Busque, F.; Ruiz-Molina, D., The Chemistry Behind Catechol-Based Adhesion. Angew. Chem. Int. Ed. Engl. 2018.

18. Haslam, E., Natural Polyphenols (Vegetable Tannins) as Drugs: Possible Modes of Action. J. Nat. Prod. 1996, 59 (2), 205-215. 
19. Chakrabarty, T.; Pérez-Manríquez, L.; Neelakanda, P.; Peinemann, K.-V., Bioinspired Tannic Acid-Copper Complexes as Selective Coating for Nanofiltration Membranes. Sep. Purif. Technol. 2017, 184, 188-194.

20. Guo, J.; Ping, Y.; Ejima, H.; Alt, K.; Meissner, M.; Richardson, J. J.; Yan, Y.; Peter, K.; von Elverfeldt, D.; Hagemeyer, C. E.; Caruso, F., Engineering Multifunctional Capsules through the Assembly of Metal-Phenolic Networks. Angew. Chem. Int. Ed. Engl. 2014, 53 (22), 5546-5551.

21. Yun, G.; Besford, Q. A.; Johnston, S. T.; Richardson, J. J.; Pan, S.; Biviano, M.; Caruso, F., Self-Assembly of Nano- to Macroscopic Metal-Phenolic Materials. Chem. Mat. 2018, 30 (16), 5750-5758.

22. Rahim, M. A.; Ejima, H.; Cho, K. L.; Kempe, K.; Müllner, M.; Best, J. P.; Caruso, F., Coordination-Driven Multistep Assembly of Metal-Polyphenol Films and Capsules. Chem. Mat. 2014, 26 (4), 1645-1653.

23. Chen, Y.; Liu, Q., Oxidant-Induced Plant Phenol Surface Chemistry for Multifunctional Coatings: Mechanism and Potential Applications. J. Membr. Sci. 2018.

24. Ball, V., Stabilization of [Poly(Allylamine)-Tannic Acid]N Multilayer Films in Acidic and Basic Conditions after Crosslinking with Naio4. RSC Adv. 2015, 5 (69), 55920-55925.

25. Devlin, H. R.; Harris, I. J., Mechanism of the Oxidation of Aqueous Phenol with Dissolved Oxygen. Ind. Eng. Chem. Fundamen. 1984, 23 (4), 387-392.

26. Hanton, L. R.; Hunter, C. A.; Purvis, D. H., Structural Consequences of a Molecular Assembly That Is Deficient in Hydrogen-Bond Acceptors. J. Chem. Soc. Chem. Commun. 1992, (16), 1134-1136.

27. Sharma, C. V. K.; Panneerselvam, K.; Pilati, T.; Desiraju, G. R., Molecular Recognition Involving an Interplay of $\mathrm{O}-\mathrm{H} \cdots \mathrm{O}, \mathrm{C}-\mathrm{H} \cdots \mathrm{O}$ and $\pi \cdots \pi$ Interactions. The Anomalous Crystal Structure of the 1: 1 Complex 3, 5-Dinitrobenzoic Acid4-(N, N-Dimethylamino) Benzoic Acid. J. Chem. Soc., Perkin Trans. 2 1993, (11), 2209-2216.

28. Steelink, C.; Tollin, G., Stable Free Radicals in Soil Humic Acid. Biochim. Biophys. Acta 1962, 59 (1), 25-34.

29. Haslam, E., Practical Polyphenolics: From Structure to Molecular Recognition and Physiological Action. Cambridge University Press: 1998.

30. Poncet-Legrand, C.; Cabane, B.; Bautista-Ortin, A. B.; Carrillo, S.; Fulcrand, H.; Perez, J.; Vernhet, A., Tannin Oxidation: Intra- Versus Intermolecular Reactions. Biomacromolecules 2010, 11 (9), 2376-2386.

31. Ball, V.; Meyer, F., Deposition Kinetics and Electrochemical Properties of Tannic Acid on Gold and Silica. Colloids and Surf. A 2016, 491 (Supplement C), 12-17.

32. Geißler, S.; Barrantes, A.; Tengvall, P.; Messersmith, P. B.; Tiainen, H., Deposition Kinetics of Bioinspired Phenolic Coatings on Titanium Surfaces. Langmuir 2016, 32 (32), 80508060 .

33. Liu, C. H., P, M, Catalytic Effects of HydroxyAluminum and Silicic Acid on Catechol Humification. In Humic Substances: Versatile Components of Plants, Soils and Water, Davies, E. A. G. a. G., Ed. 2000.

34. Barnum, D. W., Catechol Complexes with Silicon. Inorg. Chem. 1970, 9 (8), 1942-1943.

35. Weiss, A.; Herzog, A., Isolation and Characterization of a Silicon-Organic Complex from Plants. In Biochemistry of Silicon and Related Problems, Bendz, G.; Lindqvist, I.; Runnström-Reio, V., Eds. Springer US: Boston, MA, 1978; pp 109-127.

36. Caulfield, M. J.; Russo, T.; Solomon, D. H., Complexes of Benzene-1,2-Diol Mannich Bases. I. Novel Hexacoordinate
Zwitterionic Silicon(IV) Complexes. Austr. J. Chem. 2001, 54 (6), 375-381.

37. Johannsmann, D.; Reviakine, I.; Richter, R. P., Dissipation in Films of Adsorbed Nanospheres Studied by Quartz Crystal Microbalance (QCM). Anal. Chem. 20o9, 81 (19), 8167-8176.

38. Park, T.; Kim, W. I.; Kim, B. J.; Lee, H.; Choi, I. S.; Park, J. H.; Cho, W. K., Salt-Induced, Continuous Deposition of Supramolecular Iron(III)-Tannic Acid Complex. Langmuir 2018, 34 (41), 12318-12323.

39. Tollin, G.; Steelink, C., Biological Polymers Related to Catechol: Electron Paramagnetic Resonance and Infrared Studies of Melanin, Tannin, Lignin, Humic Acid and Hydroxyquinones. Biochim. Biophys. Acta 1966, 112 (2), 377-379.

40. Araujo, P. Z.; Morando, P. J.; Blesa, M. A., Interaction of Catechol and Gallic Acid with Titanium Dioxide in Aqueous Suspensions. 1. Equilibrium Studies. Langmuir 2005, 21 (8), 3470-3474.

41. Terranova, U.; Bowler, D. R., Adsorption of Catechol on $\mathrm{TiO}_{2}$ Rutile (100): A Density Functional Theory Investigation. J. Phys. Chem. C 2010, 114 (14), 6491-6495.

42. Lin, Y.-L.; Wang, T.-J.; Jin, Y., Surface Characteristics of Hydrous Silica-Coated TiOz Particles. Powder Technol. 2002, 123 (2), 194-198.

43. Larsson, E. M.; Langhammer, C.; Zorić, I.; Kasemo, B., Nanoplasmonic Probes of Catalytic Reactions. Science 2009, 326 (5956), 1091.

44. Keiji Kanazawa, K.; Gordon, J. G., The Oscillation Frequency of a Quartz Resonator in Contact with Liquid. Anal. Chim. Acta 1985, 175, 99-105.

45. Höök, F.; Kasemo, B.; Nylander, T.; Fant, C.; Sott, K.; Elwing, H., Variations in Coupled Water, Viscoelastic Properties, and Film Thickness of a Mefp-1 Protein Film During Adsorption and Cross-Linking: A Quartz Crystal Microbalance with Dissipation Monitoring, Ellipsometry, and Surface Plasmon Resonance Study. Anal. Chem. 2001, 73 (24), 57965804 .

46. Henrie, J.; Kellis, S.; Schultz, S. M.; Hawkins, A., Electronic Color Charts for Dielectric Films on Silicon. Opt. Express 2004, 12 (7), 1464-1469.

47. Wong, S. K.; Sytnyk, W.; Wan, J. K. S., Electron Spin Resonance Study of the Self-Disproportionation of Some Semiquinone Radicals in Solution. Can. J. Chem. 1972, 50 (18), 3052-3057.

48. Socrates, G., Infrared and Raman Characteristic Group Frequencies : Tables and Charts. Wiley: Chichester, 2004.

49. Arshad, M.; Beg, A.; Siddiqui, Z. A., Infrared Spectroscopic Investigation of Tannins. Angew. Makromol. Chem. 1969, 7 (1), 67-78.

50. Bernsmann, F.; Ball, V.; Addiego, F.; Ponche, A.; Michel, M.; Gracio, J. J. d. A.; Toniazzo, V.; Ruch, D. Dopamine-Melanin Film Deposition Depends on the Used Oxidant and Buffer Solution. Langmuir 2011, 27 (6), 2819-2825.

51. Yoshino, K.; Kotaka, M.; Okamoto, M.; Kakihana, H., 11B-NMR Study of the Complex Formation of Borate with Catechol and L-Dopa. Bull. Chem. Soc. Jpn. 1979, 52 (10), 30053009 .

52. Murthy, M. K.; Hill, H., Studies in Germanium Oxide Systems: III, Solubility of Germania in Water. J. Am. Ceram. Soc. 1965, 48 (2), 109-110.

53. Pichet, P.; Benoit, R. L., Complexes of Germanium (IV) with Anions of o-diphenols and Their Stability Constants. Inorg. Chem. 1967, 6 (8), 1505-1509.

54. Antikainen, P. J., A Comparative Study on the Chelate Fromation between Germanic Acid and Some Glycols and 
Polyalcohols in Aqueous Solutions. Acta Chem. Scand. 1959, 13, 312-133.

55. Yang, L.; Han, L.; Ren, J.; Wei, H.; Jia, L., Coating Process and Stability of Metal-Polyphenol Film. Colloids and Surf. A 2015, 484 (Supplement C), 197-205.

56. Shindo, H.; Huang, P. M., Catalytic Effects of Manganese (IV), Iron(III), Aluminum, and Silicon Oxides on the Formation of Phenolic Polymers. Soil Sci. Soc. Am. J. 1984, 48 (4), 927-934.

57. Shindo, H.; Huang, P. M., The Catalytic Power of Inorganic Components in the Abiotic Synthesis of Hydroquinone-Derived Humic Polymers. Appl. Clay Sci. 1985, 1 (1), 71-81.

58. Vernhet, A.; Dubascoux, S.; Cabane, B.; Fulcrand, H.; Dubreucq, E.; Poncet-Legrand, C., Characterization of Oxidized Tannins: Comparison of Depolymerization Methods, Asymmetric Flow Field-Flow Fractionation and Small-Angle XRay Scattering. Anal. Bioanal. Chem. 2011, 401 (5), 1559-1569.

59. Mian, S. A.; Gao, X.; Nagase, S.; Jang, J., Adsorption of Catechol on a Wet Silica Surface: Density Functional Theory Study. Theor. Chem. Acc. 2011, 130 (2), 333-339.

6o. Critchlow, A.; Haslam, E.; Haworth, R. D.; Tinker, P. B.; Waldron, N. M., The Oxidation of Some Pyrogallol and Purpurogallin Derivatives. Tetrahedron 1967, 23 (6), 2829-2847.

61. Ma, H.; Textor, M.; Clark, R. L.; Chilkoti, A., Monitoring Kinetics of Surface Initiated Atom Transfer Radical Polymerization by Quartz Crystal Microbalance with Dissipation. Biointerphases 2006, 1 (1), 35-39.

62. Ward, M. D.; Buttry, D. A., In Situ Interfacial Mass Detection with Piezoelectric Transducers. Science 1990, 249 (4972), 1000-1007.

63. Lucklum, R.; Behling, C.; Hauptmann, P., Role of Mass Accumulation and Viscoelastic Film Properties for the Response of Acoustic-Wave-Based Chemical Sensors. Anal. Chem. 1999, 71 (13), 2488-2496.

64. Schmidt, O. T.; Demmler, K., Optisch Aktive 2,3,4,2' ,3', 4' -Hexamethoxy-Diphenyl-Dicarbonsäure-6,6'. XIII. Mitteilung Über Natürliche Gerbstoffe. Liebigs Ann. 1952, 576 (2), 85-93.

65. Albertsson, A.-C.; Varma, I. K., Recent Developments in Ring Opening Polymerization of Lactones for Biomedical Applications. Biomacromolecules 2003, 4 (6), 1466-1486. 


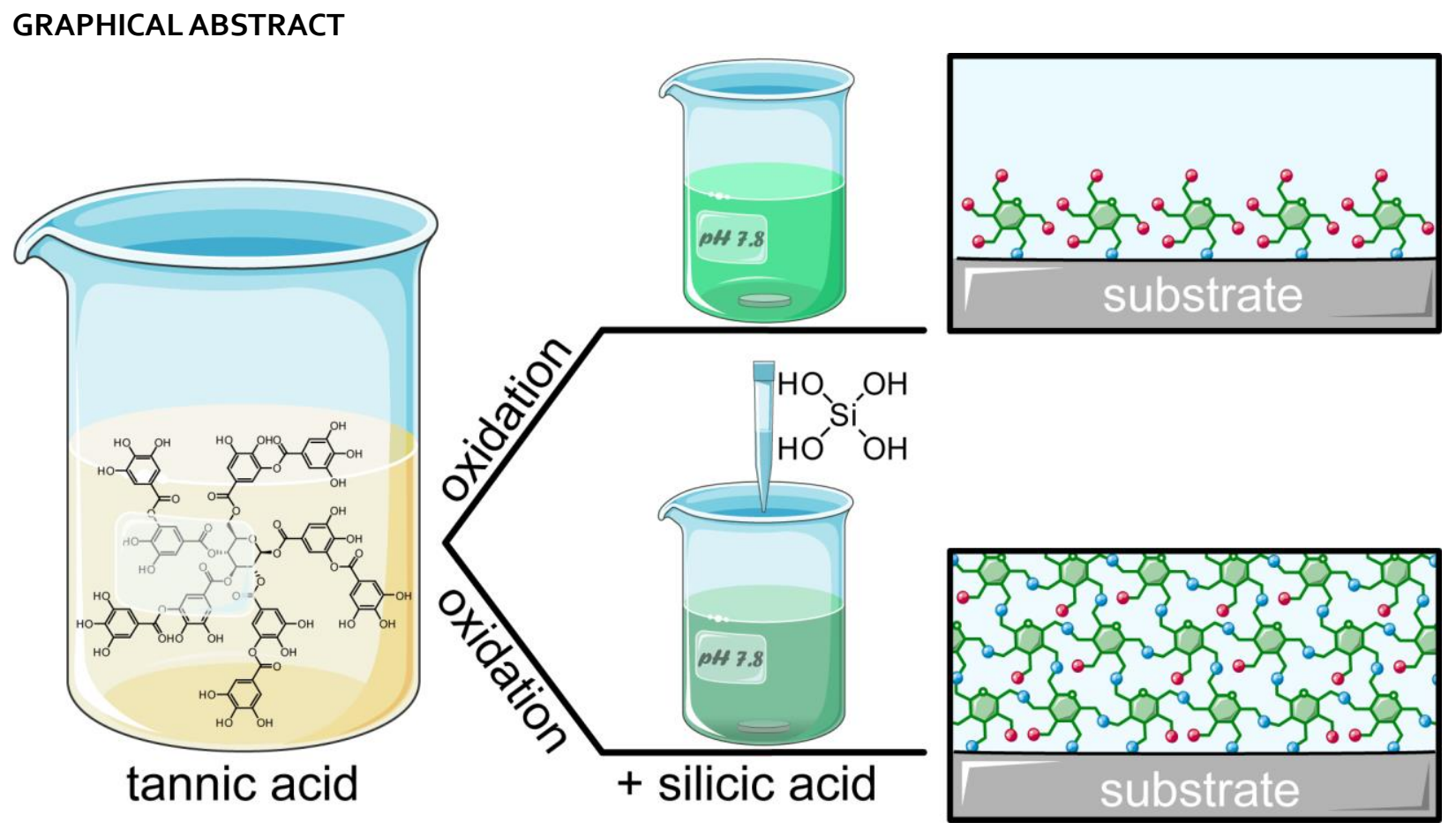

Figure 8: For Table of Contents Only 